This is a self-archiving document (manuscript version):

Improved Pt-utilization efficiency of low Pt-loading PEM fuel cell electrodes using direct membrane deposition

By: Breitwieser, Matthias; Klingele, Matthias; Britton, Benjamin;

Holdcroft, Steven; Zengerle, Roland; Thiele, Simon

Published in: Electrochemistry Communications

Volume 60, November 2015, Pages 168-171 (Please be aware: Page numbering in this manuscript can be different to published version!)

Publisher: Elsevier | Year: 2015

DOI: 10.1016/j.elecom.2015.09.006

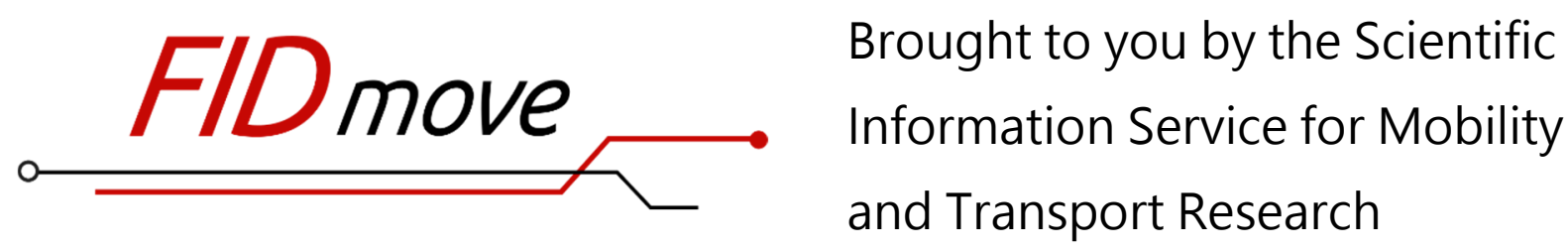

Fachinformationsdienst Mobilitäts- und Verkehrsforschung

Website: www.fid-move.de

Repository: publish.fid-move.de

Contact: publish@fid-move.de

(C) 2020. This manuscript version is made available under the CC-BYNC-ND 4.0 license.

http://creativecommons.org/licenses/by-nc-nd/4.0/ 


\title{
Improved Pt-utilization efficiency of low Pt-loading PEM fuel cell electrodes using direct membrane deposition
}

\author{
Matthias Breitwieser ${ }^{\mathrm{a}, \mathrm{b}, *}$, Matthias Klingele ${ }^{\mathrm{a}}$, Benjamin Britton ${ }^{\mathrm{c}}$, Steven Holdcroft ${ }^{\mathrm{c}}$, \\ Roland Zengerle ${ }^{\mathrm{a}, \mathrm{b}}$, Simon Thiele ${ }^{\mathrm{a}, \mathrm{b}, \mathrm{d}}$ \\ a Laboratory for MEMS Applications, IMTEK Department of Microsystems Engineering, University of Freiburg, Georges-Koehler-Allee 103, 79110 Freiburg, Germany \\ b Hahn-Schickard, Georges-Koehler-Allee 103, 79110 Freiburg, Germany \\ c Department of Chemistry, Simon Fraser University, 8888 University Drive, Burnaby, Canada V5A-1S6 \\ d FIT, University of Freiburg, Georges-Koehler-Allee 105, 79110 Freiburg, Germany
}

A B S T R A C T

Direct membrane deposition was used to produce record platinum catalyst utilization efficiency polymer electrolyte membrane fuel cells. The novel membrane fabrication technique was applied to gas diffusion electrodes with low Pt-loadings of 0.102 and $0.029 \mathrm{mg} / \mathrm{cm}^{2}$. Under oxygen atmosphere and $300 \mathrm{kPa} \mathrm{abs}_{\text {s }}$ total pressure, $88 \mathrm{~kW} / \mathrm{g}_{\mathrm{Pt}}$ cathodic catalyst utilization efficiency with a symmetrical Pt-loading of $0.029 \mathrm{mg} / \mathrm{cm}^{2}$ on the anode and cathode side was achieved. This is 2.3 times higher than the Pt-utilization efficiency of a reference fuel cell prepared using a commercial Nafion N-211 membrane and identical catalyst layers, emphasizing that the improvement is purely attributable to the novel membrane fabrication technique. This value represents the highest Pt-utilization efficiency reported in literature. The results strongly motivate the application of employing direct membrane deposition techniques to prepare low resistance polymer electrolyte thin films in order to compensate for kinetic losses introduced when using low catalyst loadings.

\section{Introduction}

A recent report confirmed that the high cost of platinum (Pt) used in the catalyst layer is still the main obstacle for the commercialization of PEM fuel cells. The reduction of the total Pt-loading from $0.4 \mathrm{mg} / \mathrm{cm}^{2}$ to lower loadings in the range of $0.1 \mathrm{mg} / \mathrm{cm}^{2}$ would dramatically decrease the cost of MEA production [1-3].

Up to now several approaches have been pursued to achieve acceptable power densities with low Pt-loadings [2,4-7]. A high Ptutilization efficiency of $20 \mathrm{~kW} / \mathrm{g}_{\mathrm{Pt}}$ was reported by Martin et al. using electrosprayed catalyst layers (CLs) with an ultra-low cathode loading of $0.012 \mathrm{mg} / \mathrm{cm}^{2}$ [8]. Cavarroc et al. published a cathodic Pt-utilization efficiency of $20 \mathrm{~kW} / \mathrm{g}_{\mathrm{Pt}}$ for a magnetron co-sputtered catalyst layer with a cathodic Pt-loading of $0.012 \mathrm{mg} / \mathrm{cm}^{2}$ in conjunction with a commercial $\mathrm{N}-212$ membrane and $1 \mathrm{mg} / \mathrm{cm}^{2}$ Pt-loading in the anode [9]. Shukla et al. recently reported high power densities with inkjetprinted catalyst layers, resulting in a high cathodic Pt-utilization efficiency of $47.6 \mathrm{~kW} / \mathrm{g}$ at a cathode loading of $0.026 \mathrm{mg}$ Pt [10]. All these reports included polarization measurements under optimized

\footnotetext{
* Corresponding author at: Laboratory for MEMS Applications, IMTEK Department of Microsystems Engineering, University of Freiburg, Georges-Koehler-Allee 103, 79110 Freiburg, Germany.
}

http://dx.doi.org/10.1016/j.elecom.2015.09.006
Keywords:

Hydrogen fuel cell

PEMFC

Low Pt-loading

Direct membrane deposition

Pt-efficiency

Membrane 
operation conditions $\left(\mathrm{H}_{2} / \mathrm{O}_{2}\right.$ atmosphere, $300 \mathrm{kPa}$ abs pressure). The highest cathodic Pt-utilization efficiency to date has been reported by Martin et al., where $60-70 \mathrm{~kW} / \mathrm{g}_{\mathrm{Pt}}$ was achieved for catalyst layers with Pt-loadings of $0.01 \mathrm{mg} / \mathrm{cm}^{2}$ [11].

Due to the increased kinetic activation losses at ultra-low Pt loadings, the cell voltage drops significantly, even under low current densities. In combination with the ionic resistances, this effect leads to a significant loss of cell voltage and low maximum power densities with increasing current density, even for highly optimized conditions using $\mathrm{O}_{2}$ under backpressure to avoid mass transport limitations. We postulate that the low power densities observed using ultra-low Pt-loadings can be compensated by significant reduction of the ionic resistance, which is usually in the range of about $50-150 \mathrm{mOhm} \mathrm{cm}^{2}$ [12].

In this work, Ohmic losses within the fuel cell are addressed by using a direct membrane deposition (DMD) technique in the MEA fabrication process. DMD was recently introduced by Klingele et al. as a new technique to fabricate 8-15 $\mu \mathrm{m}$ thin ionomer films with excellent ionic conduction enabling high fuel cell power densities beyond $4 \mathrm{~W} / \mathrm{cm}^{2}$ using $\mathrm{H}_{2} / \mathrm{O}_{2}$ and $300 \mathrm{kPa}_{\mathrm{abs}}$ pressure [13]. By using DMD the conventionally free standing membrane is replaced by two ionomer layers which are directly deposited onto anode and cathode gas diffusion electrodes (GDE). Nevertheless in the work of Klingele et al., high anodic and cathodic Pt-loadings of $0.5 \mathrm{mg} / \mathrm{cm}^{2}$ were used. In this instance, we apply this method to GDEs with low Pt loadings of 0.102 and $0.029 \mathrm{~g} / \mathrm{cm}^{2}$ on each the anode and cathode. 


\section{Methods}

The inkjet-printing process is described in detail in the work of Klingele et al. [13] and is applied in this work to $5 \mathrm{~cm}^{2}$ GDEs with 2 different Pt-loadings: 0.102 and $0.029 \mathrm{mg} / \mathrm{cm}^{2}$. The catalyst layers were fabricated by spray coating carbon supported catalyst ink on top of Sigracet BC 24 gas diffusion media. Catalyst ink comprised $1 \mathrm{wt} \%$ solids in $1: 1 \mathrm{MeOH}: \mathrm{H}_{2} \mathrm{O}$, the solids $30 \mathrm{wt} \%$ ionomer (Nafion D520) and $70 \mathrm{wt} \%$ Pt/C (46.4 wt\% Pt supported on graphitized C, TKK TEC10E50E), was formed by adding the ionomer dispersion dropwise to a stirred dispersion of the catalyst in the dispersion medium. Catalyst ink was applied to the gas diffusion media atop a heated vacuum table at $85^{\circ} \mathrm{C}$ via a sonicating-head spray coater (Sono-Tek Exacta-Coat), with flow rates accurately controlled by syringe pumping, with each layer drying near-instantaneously. The reported Pt-loadings of all samples were determined by weighing the GDEs and CCMs before and after the catalyst ink spray coating. The ionomer dispersion used for membrane fabrication was fabricated by diluting 1 volumetric part of Nafion D2020 dispersion with two volumetric parts of 2-propanol. The ionomer films were printed with a BioFluidix Pipejet inkjet-printer. Compared to the work of Klingele et al. the membrane printing parameters were modified to a downstroke velocity of $127 \mu \mathrm{m} / \mathrm{ms}$ and a stroke length of $27 \mu \mathrm{m}$ of the printers piezo actuator which enhanced the reliability of the printing process. The fuel cell was assembled by placing two GDEs of identical loading, covered by the printed membrane layers face-toface with a thin PTFE subgasket in between. The $50 \mu \mathrm{m}$ thin subgasket reduced the active fuel cell area to $4 \mathrm{~cm}^{2}$ and ensured that no parasitic currents or gas crossover could occur at the edges of the GDEs. N-211 (25 $\mu \mathrm{m}$ membrane) based catalyst coated membranes (CCMs) with an active fuel cell area of $5 \mathrm{~cm}^{2}$ were used as references (with corresponding catalyst layers and gas diffusion media). All shown Pt utilization or loading values, current densities and power densities are given in normalized units per $\mathrm{cm}^{2}$ to account for the different active fuel cell areas of the DMD and the reference fuel cell.

For fuel cell characterization, a Scribner 850e system was used. To create comparable testing conditions to those used in literature [8-10], we operated the fuel cells with flows of $0.5 \mathrm{~L} / \mathrm{min}$ of $\mathrm{H}_{2}$ and $\mathrm{O}_{2}$. The cell temperature was $80{ }^{\circ} \mathrm{C}$ and the relative humidity ( $\mathrm{RH}$ ) was adjusted to $75 \%$. A back pressure of $200 \mathrm{kPa}$ on each side was applied to the fuel cell, resulting in a pressurized environment of $300 \mathrm{kPa}_{\mathrm{abs}}$. The high frequency resistance (HFR) was measured with an integrated frequency response analyzer during the polarization experiments. To extract the ionic contribution to the HFR (ionic CL resistance, CL-PEM contact resistances, PEM resistance) the electronic contribution (cabling, flow fields, gas diffusion electrodes) is subtracted according to a previously published procedure [13,14]: All used gas diffusion electrodes without membrane layers were assembled with the catalyst layers facing each other and a subgasket in between. The identical torque of $5 \mathrm{Nm}$ was applied to the fuel cell fixture. By sweeping the current, the electrical resistance was determined to be $17.4 \pm 0.5 \mathrm{~m}$ $\Omega \mathrm{cm}^{2}$, which is in accordance with published values for compressed Sigracet BC material [14]. This value was subtracted from the HFRvalues measured by in situ impedance spectroscopy, yielding the purely ionic resistance. The membrane and catalyst layer thicknesses were investigated with a scanning electron microscope (Phenom Pro SEM) using an electron acceleration voltage of $10 \mathrm{kV}$. Cross-sections were prepared by fracturing liquid nitrogen-cooled MEAs.

\section{Results \& discussion}

The cross-sections shown in Fig. 1 revealed that the membrane thickness ranged from 8 to $15 \mu \mathrm{m}$. This thickness distribution is comparable to the work in Klingele et al. [13], and below that of 

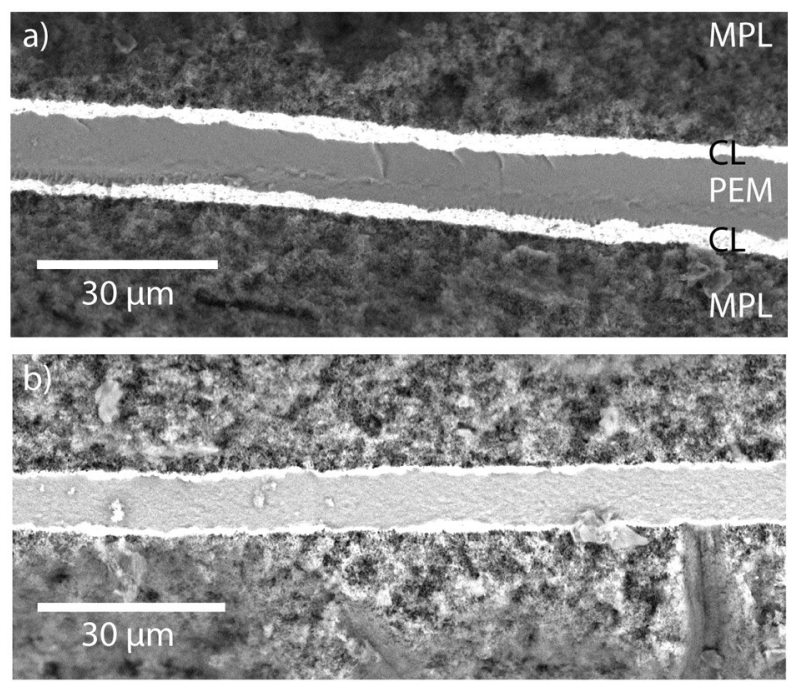

Fig. 1. SEM-images of cryo-fractured cross sections of DMD-MEAs with different Pt-loading, showing the micro porous layer (MPL), catalyst layer (CL) and polymer electrolyte membrane (PEM). a) $0.102 \mathrm{mg} / \mathrm{cm}^{2}$ anodic/cathodic Pt-loading, b) $0.029 \mathrm{mg} / \mathrm{cm}^{2} \mathrm{Pt}-$ loading.

the commercially-available membrane $\mathrm{N}-211(25 \mu \mathrm{m})$. From the SEM image analysis, the catalyst layer thicknesses were observed to be $2-4 \mu \mathrm{m}$ for $0.102 \mathrm{mg}_{\mathrm{Pt}} / \mathrm{cm}^{2}$ loading and $0.5-1.5 \mu \mathrm{m}$ for $0.029 \mathrm{mg} / \mathrm{cm}^{2}$ loading. Further ion beam sectioning and high-resolution SEM imaging proofed that DMD only infiltrates the surface-near pores of the catalyst layer up to a depth of 100-200 nm [15]. Thus the oxygen diffusion in the thin catalyst layers investigated in this work is not affected. On the contrary, as claimed in the publication of Klingele et al., the 3D-CL-PEM interface is believed to improve ionic connection and charge transfer between CL and PEM resulting in higher fuel cell performance [13].

The polarization data for the two differently loaded DMD samples are shown in Fig. 2, together with the corresponding reference samples with $\mathrm{N}-211$ membrane. For $0.102 \mathrm{mg} / \mathrm{cm}^{2}$ anodic/cathodic loading, an improvement of $51 \%$ was found for the DMD sample $\left(2.93 \mathrm{~W} / \mathrm{cm}^{2}\right)$ in comparison to the CCM reference $\left(1.93 \mathrm{~W} / \mathrm{cm}^{2}\right)$. The comparable open circuit voltage (OCV) values of about $965 \mathrm{mV}$ signal a good performance in terms of hydrogen crossover and internal shorting. A maximum power density of $2.56 \mathrm{~W} / \mathrm{cm}^{2}$ was found for the DMD fuel cell with 0.029 $\mathrm{mg} / \mathrm{cm}^{2}$ Pt-loading. This corresponds to a very high Pt-utilization of about $88 \mathrm{~kW} / \mathrm{g}_{\mathrm{Pt}}$. $( \pm 3 \mathrm{~kW} / \mathrm{g}$, assuming a Pt-loading uncertainty of $\pm 0.0005 \mathrm{mg} / \mathrm{cm}^{2}$ ). To our knowledge, this is the highest reported value in literature. The reference sample with the identical Pt-loading showed a maximum power density of only $1.1 \mathrm{~W} / \mathrm{cm}^{2}$. This corresponds to an improvement of $132 \%$ compared to the CCM reference.

The enhanced power density of the DMD-prepared fuel cell is partially attributed to a strongly reduced ionic resistance of the DMD solid polymer electrolyte compared to the N-211 references (see Fig. 2, half-filled symbols). Using a cathodic Pt-loading of $0.102 \mathrm{mg} / \mathrm{cm}^{2}$ an ionic resistance of $12 \mathrm{mOhm} \mathrm{cm}^{2}$ was calculated

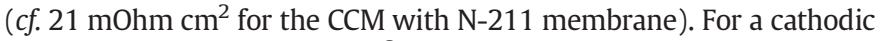
Pt-loading of $0.029 \mathrm{mg} / \mathrm{cm}^{2}$ the same measurement revealed $15 \mathrm{mOhm} \mathrm{cm}^{2}$ ( $c f .27 \mathrm{mOhm} \mathrm{cm}^{2}$ for the CCM with $\mathrm{N}-211$ membrane). These very low resistances are believed to impact the polarization characteristics and partially explain the significantly improved cell performance of the DMD samples. Analyzing the ionic resistances shown in Fig. 2 (half-filled symbols), a slight rise of the ionic resistance values with decreasing Pt-loading was observed. Even though the membrane thicknesses of both examined samples were comparable (as shown by the SEM-images in Fig. 1 and ensured by the use of $\mathrm{N}-211$ as reference), a higher ionic resistance value for the sample with $0.029 \mathrm{mg} / \mathrm{cm}^{2}$ anodic/cathodic Pt-loading was obtained than with the fuel cell with $0.102 \mathrm{mg} / \mathrm{cm}^{2}$ Pt-loading. Due to the comparable membrane thicknesses 
a)
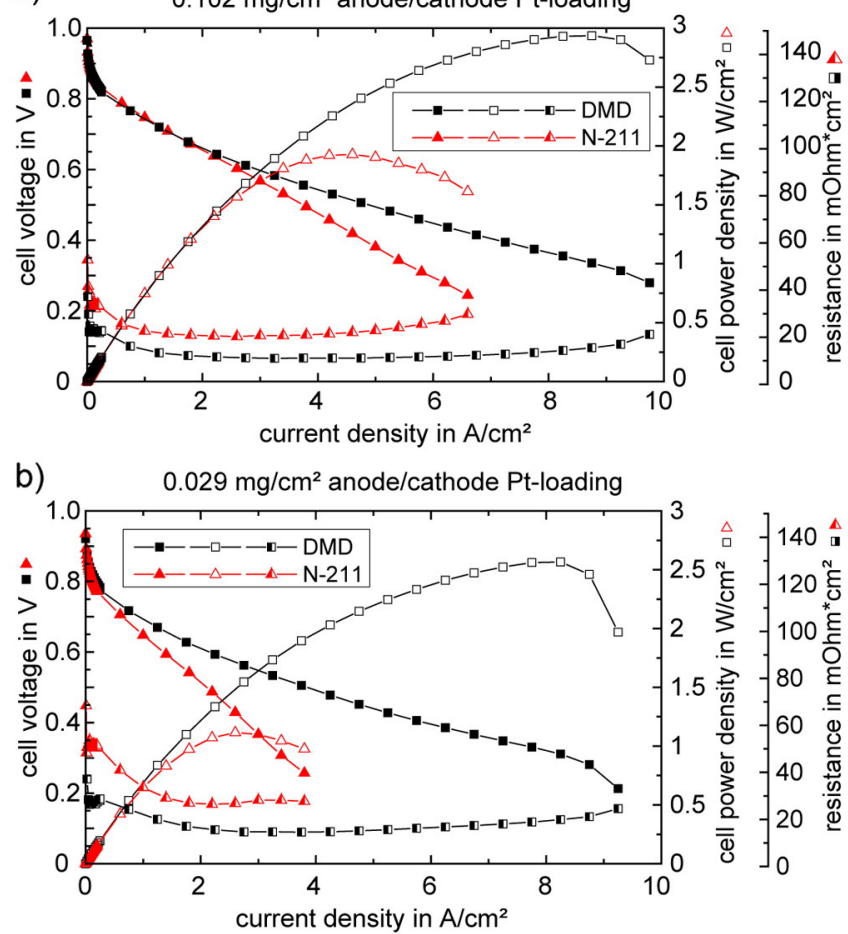

c)

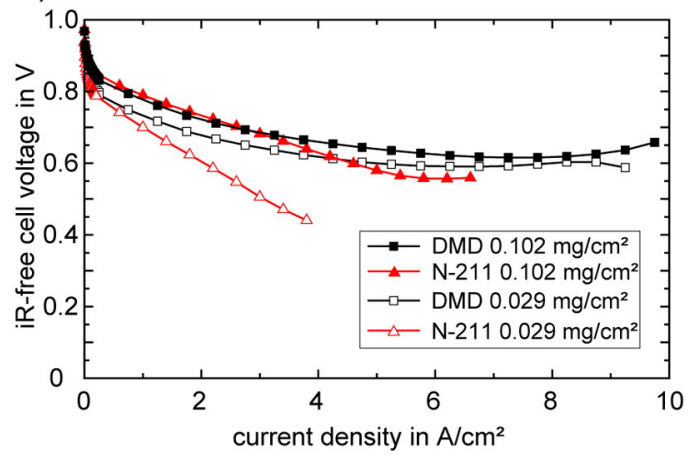

Fig. 2. Polarization data for fuel cells with low Pt-loading: a) $0.102 \mathrm{mg} / \mathrm{cm}^{2}$, b) $0.029 \mathrm{mg} / \mathrm{cm}^{2}$. For each loading a DMD and a conventional CCM fuel cell with N-211 membrane are compared. The voltage characteristic is shown in closed symbols, the power density is represented by open symbols, and the ionic resistance is depicted in half-filled symbols. In Fig. 2c) the $\mathrm{iR}$-free representation of the polarization data is shown. The operation conditions were: $0.5 / 0.5 \mathrm{l} / \mathrm{min}_{2} / \mathrm{O}_{2}$ fixed flow, $80{ }^{\circ} \mathrm{C}, 75 \% \mathrm{RH}, 300 / 300 \mathrm{kPa}_{\mathrm{abs}}$.

of both tested fuel cells, the variation of the ionic resistance is believed to be related to a decreasing ionic conductivity of the catalyst layer or a varying humidification of the ionomer.

From the iR-free representation in Fig. 2c) more information can be drawn. For current densities higher than $1 \mathrm{~A} / \mathrm{cm}^{2}$ an increasing deviation is found between the CCM and the DMD samples in the iR-free representation. A lower decrease in voltage was found for both DMD samples, compared to CCM fuel cells, with raising current densities. For the $0.102 \mathrm{mg} / \mathrm{cm}^{2}$ samples the effect is not as obvious, but for the $0.029 \mathrm{mg} / \mathrm{cm}^{2}$ CCM fuel cell a significant deviation between the CCM and the DDM sample is observed. Thus, apart from the low ionic resistance, another reason for the increased power density in the high current density range may be an improved mass transport. This is in accordance with recent studies, where increasing resistances at low Pt-loading were observed [16-19]. Reported transport resistances in catalyst layers with low Pt-loading due to deteriorated oxygen diffusion [16] should not be evident in the high frequency regime of the HFRmeasurement in this work [20] but affect the polarization behavior in the high current density range. However, the different phenomena of 
rising resistances in fuel cells with low Pt-loading and their underlying effects are still under investigation [16].

\section{Conclusion}

In previous work, direct membrane deposition (DMD) was introduced as new MEA manufacturing technique. Here, DMD was employed on gas diffusion electrodes with different levels of low Pt-loading. Spray-coated state-of-the-art electrodes were used as catalyst layers. With that, a cathodic Pt-utilization efficiency of $88 \mathrm{~kW} / \mathrm{g}_{\mathrm{Pt}}$ at a Ptloading of $0.029 \mathrm{mg} / \mathrm{cm}^{2}$ was obtained. To our knowledge, this is the highest reported Pt-utilization efficiency in hydrogen fuel cells. The significantly lower ionic resistance and improved power density in the high current density range compared to state-of-the-art CCM fuel cells were found to enable the high Pt-utilization efficiency. Thus future work will focus on a full understanding of the improved performance to reveal all reasons for the improved performance of DMD fuel cell with low Pt-loading. Finally the balance between anode and cathode Pt-loading should be optimized to further enhance the Pt-utilization efficiency of DMD fuel cells.

\section{Conflict of interest}

The authors declare no competing interests.

\section{Acknowledgments}

This work was funded by the German Federal Ministry of Education BMBF within the project GECKO (grant number 03SF0454C). S. Holdcroft thanks the Natural Sciences and Engineering Research Council of Canada (NSERC) for funding.

\section{References}

[1] Wolfgang Bernhart, Stefan Riederle, Manuel Yoon, Fuel cells-a realistic alternative for zero emission? Roland Berger Strategy Consultants-Study2013.

[2] A. Ohma, T. Mashio, K. Sato, H. Iden, Y. Ono, K. Sakai, K. Akizuki, S. Takaichi, K. Shinohara, Analysis of proton exchange membrane fuel cell catalyst layers for reduction of platinum loading at Nissan, Electrochim. Acta 56 (2011) 10832-10841.

[3] USDRIVE, Fuel Cell Technical Team Roadmap, 2013.

[4] A. Caillard, C. Charles, D. Ramdutt, R. Boswell, P. Brault, Effect of Nafion and platinum content in a catalyst layer processed in a radio frequency helicon plasma system, J. Phys. D. Appl. Phys. 42 (2009), 045207.

[5] W. Zhang, P.N. Pintauro, High-performance nanofiber fuel cell electrodes, ChemSusChem 4 (2011) 1753-1757.

[6] H. Su, T.-C. Jao, O. Barron, B.G. Pollet, S. Pasupathi, Low platinum loading for high temperature proton exchange membrane fuel cell developed by ultrasonic spray coating technique, J. Power Sources 267 (2014) 155-159.

[7] R. O'Hayre, S.-J. Lee, S.-W. Cha, F. Prinz, A sharp peak in the performance of sputtered platinum fuel cells at ultra-low platinum loading, J. Power Sources 109 (2002) 483-493.

[8] S. Martin, P.L. Garcia-Ybarra, J.L. Castillo, High platinum utilization in ultra-low Pt loaded PEM fuel cell cathodes prepared by electrospraying, Int. J. Hydrog. Energ. 35 (2010) 10446-10451.

[9] M. Cavarroc, A. Ennadjaoui, M. Mougenot, P. Brault, R. Escalier, Y. Tessier, J. Durand, S. Roualdès, T. Sauvage, C. Coutanceau, Performance of plasma sputtered fuel cell electrodes with ultra-low Pt loadings, Electrochem. Commun. 11 (2009) 859-861.

[10] S. Shukla, K. Domican, K. Karan, S. Bhattacharjee, M. Secanell, Analysis of low platinum loading thin polymer electrolyte fuel cell electrodes prepared by inkjet printing, Electrochim. Acta 156 (2015) 289-300.

[11] S. Martin, B. Martinez-Vazquez, P.L. Garcia-Ybarra, J.L. Castillo, Peak utilization of catalyst with ultra-low Pt loaded PEM fuel cell electrodes prepared by the electrospray method, J. Power Sources 229 (2013) 179-184.

[12] F. Barbir, PEM Fuel Cells: Theory and Practice, 2nd ed. Elsevier Science, San Diego, 2012.

[13] M. Klingele, M. Breitwieser, R. Zengerle, S. Thiele, Direct deposition of proton exchange membranes enabling high performance hydrogen fuel cells, J. Mater. Chem. A. 3 (2015) 11239-11245.

[14] R. Jiang, C.K. Mittelsteadt, C.S. Gittleman, Through-plane proton transport resistance of membrane and ohmic resistance distribution in fuel cells, J. Electrochem. Soc. 156 (2009), B1440.

[15] S. Vierrath, M. Breitwieser, M. Klingele, R. Zengerle, S. Thiele, Properties of a direct deposited membrane (DDM) Investigating the reasons for its high performance: Poster, EMEA-conference, Bad Zwischenahn (Germany), 2015. 
[16] A.Z. Weber, A. Kusoglu, Unexplained transport resistances for low-loaded fuel-cell catalyst layers, J. Mater. Chem. A 2 (2014) 17207-17211.

[17] Yoshitaka Ono, Tetsuya Mashio, Satoshi Takaichi, Atsushi Ohma, Hiroyuki Kanesaka Kazuhiko Shinohara, The analysis of performance loss with low platinum loaded cathode catalyst layers, ECS Trans. 28 (2010) 69-78.

[18] Nobuaki Nonoyama, Shinobu Okazaki, Adam Z. Weber, Yoshihiro Ikogi, Analysis of oxygen-transport diffusion resistance in proton-exchange-membrane fuel cells, J. Electrochem. Soc. 158 (2011) B416-B423.

[19] Jon P. Owejan, Jeanette E. Owejan, Wenbin Gua, Impact of platinum loading and catalyst layer structure on PEMFC performance, J. Electrochem. Soc. 160 (2013) F824-F833.

[20] T.J. Freire, E.R. Gonzalez, Effect of membrane characteristics and humidification conditions on the impedance response of polymer electrolyte fuel cells, J. Electroanal. Chem. 503 (2001) 57-68. 